\title{
DOES CASH FLOW AFFECT INVESTMENT? EVIDENCE FROM THE ROMANIAN CAPITAL MARKET
}

\author{
Andriana PUTUNTICA ${ }^{1}$ \\ Babes-Bolyai University, Cluj-Napoca \\ Carmen Giorgiana BONACI ${ }^{2}$ \\ Babes-Bolyai University, Cluj-Napoca
}

\begin{abstract}
Our paper addresses the relation between corporate investments and cash flow. While literature agrees upon the existence of a correlation between the two, its interpretation continues to generate intense debates. We use data from a sample of 125 Romanian listed companies for the 2005-2011 period. Using a fixed effects least squares model we document a positive significant association between investments and cash flow. The results show that a 1\% cash flow fluctuation leads to a $0.27 \%$ alteration of the planned investments. We therefore add to the literature on a widely debated topic by bringing evidence in the case of Romanian listed companies.
\end{abstract}

\section{KEY WORDS}

Investments, cash flow, financial reporting, panel data, fixed effects

\section{JEL CLASSIFICATION}

$M 10, M 40, G 11$

\section{INTRODUCTION}

It is a well known fact that information provided through companies' cash flows is especially important for capital markets and investors. While cash flow related information is often used in order to make short term decisions, our paper mainly focuses on long term consequences. More precisely, we investigate whether cash flow influences long term investments and look at the details of such a potential influence in the particular case of Romanian listed companies.

Therefore, the objectives of our analysis are as follows: to investigate the existence of an association between a company's cash flow and its investments, to develop a linear econometric model which would explain the effect of the considered independent variable (cash flow) on the

${ }^{1}$ Correspondence address: Andriana Putuntica, Master student, +40.264.41.86. 52, andriana.putuntica@gmail.com, Babes-Bolyai University, Cluj-Napoca, Faculty of Economics and Business Administration, econ@econ.ubbcluj.ro, www.econ.ubbcluj.ro.

${ }^{2}$ Correspondence address: Carmen Giorgiana Bonaci, Associate professor, +40.264.41.86. 52, carmen.bonaci@econ.ubbcluj.ro, Babes-Bolyai University, Cluj-Napoca, Faculty of Economics and Business Administration, econ@econ.ubbcluj.ro,www.econ.ubbcluj.ro. 
assumed dependent variable (investments) and to validate the results of the regression analysis through the necessary tests in order to see to what extent they respond to the general research question. We expect the investments being made by a company in a certain period to display direct correlation with the company's cash flow for the same time frame.

The remainder of the paper is organized as follows. Section 1 presents a brief theoretical motivation of our paper and positions it within literature. Section 2 explains the employed research methodology. Section 3 develops the analysis and presents the obtained results. Section 4 concludes and discusses limitations of the study together with perspectives for future research.

\section{THEORETICAL GROUNDING}

Shimko (1997) emphasizes how risk managers spend significant part of their time in order to analyze the factors that can cause big cash flow fluctuations. This is especially relevant as a week cash flow can generate total chaos in companies' budgets, keeping managers away from productive work, postponing capital spends or slowing down debt reimbursement (Shimko, 1997). Stancu (2002) considers the decision to invest as being the most important one in companies' financial flow, being made together with the financing one as the market is not perfect (Stancu, 2002: 549).

The decision to invest is influenced by several factors such as tax, cost of insurance, cost of capital, etc. The factor that our analysis focuses on is companies' cash flow, our paper looking at investments' sensibility in relation to cash flow generated by the company. Theoretically speaking, chances are higher that a company will decide to invest when it records high cash flow. This can be explained as follows: internal capital could be less expensive than external ones (Fazzari et al., 1988); free cash flow related hypotheses show that managers tend to spend more than the internal available capital (Richardson, 2006); and it is possible that cash flow is correlated with investment opportunities (Ciccolo \& Fromm, 1979).

A number of previous empirical studies document a significant association between investments and cash flow. Fazzari et al.'s (1988) study uses a sample of 422 industrial companies for the 19701984 period and uses Tobin's Q as the variable reflecting the company's investment opportunities. A high level of Q tells us that companies should invest more as the value of their capital is higher than the actual price paid for it. Their assumption is that cash flow influences investments as the market is imperfect and internal capital is "less expensive" than the external one. It therefore makes sense that cash flow would play an important role in financially constrained companies' investment related decisions. Fazzari et al. (1988) also consider companies' dividend payments, documenting a stronger association between investments and cash flow for companies paying lower dividends. Kaplan \& Zingales (1997) focus on a sample of low dividends companies and analyze the particularities of companies' financing constrains by making use of information from financial statements and liquidity statements - known as a statement of maturity of assets and liabilities. Their results document that for companies having less financing constrains investments are more sensible to cash flow fluctuations, therefore concluding that high investments sensibility in relation to cash flow can not be interpreted as an indicator of companies facing financing constrains. Cleary (1999) and Baker et al. (2003) also investigate the influence of cash flow on investments, finding values such as $0.05-0.15$. More recently, Hennessy et al. (2007) document investments' sensibility to cash flow to record values such as 0.01-0.09. Summing up, we may conclude that previous studies in literature investigating the association between companies' investments and their cash flow document mixed results. 


\section{RESEARCH METHODOLOGY}

The proposed research question is approached by developing a fixed effects model for panel data. The data being used in our analysis is mainly based on accounting information taken from companies' financial statements. The companies being included in our sample are those listed on the Romanian capital market. We have eliminated from our sample financial companies as well as companies for which we were unable to find data (corresponding to the considered variables) for more than two years. The analysis being developed includes 125 companies for the 2005-2011 period, generating a number of 875 observations. The considered variables were investments, cash flow and Q (Tobin's Q) computed as follows:

$>$ Investments (Inv): representing funds being used by a company in order to purchase or modernize tangible assets (property, plants and equipments); dependent variable;

$>$ Operating cash flow (CFO): is computed through the indirect method; a comparative analysis of profit and cash flow showed that cash flow follows a more linear, less volatile tendency; independent variable;

$>$ Tobin's $Q(Q)$ : the use of this variable is based on previous studies documenting its relevance in relation to investments and cash flow, starting with Keynes who concluded that the decision to invest becomes more attractive once the value of the capital raises in relation to its cost (Abel \& Eberly, 2010); although the close correlation between cash flow and investments is a well documented one, the causality is hard to establish as both variables (investments and cash flow) are influenced by the company's profitability; this variable (Q) helps control the effect of profitability on investments; independent variable;

$>$ Social capital $(K)$ : is included as a control variable; an increase in the company's social capital is a sign of "financial health" and the company can use additional profits in order to invest in its projects; independent variable;

$>$ Sales $(S)$ : control variable used by Fazzari et al. (1988) as a determinant of capital spends; measured as turnover at the end of the year; independent variable.

The data being collected for the 125 companies for the 7 years included in our analysis is further transformed in log values (for most of the variables) for the purpose of our analysis.

\section{DEVELOPING THE ANALYSIS AND INTERPRETING THE OBTAINED RESULTS}

A first step in choosing the proper econometric model aiming to capture the association between investments and cash flow imposes the observation of its graphical representation as we can see in Graph 1 presented below:

Graph 1 Distribution of the observed variables

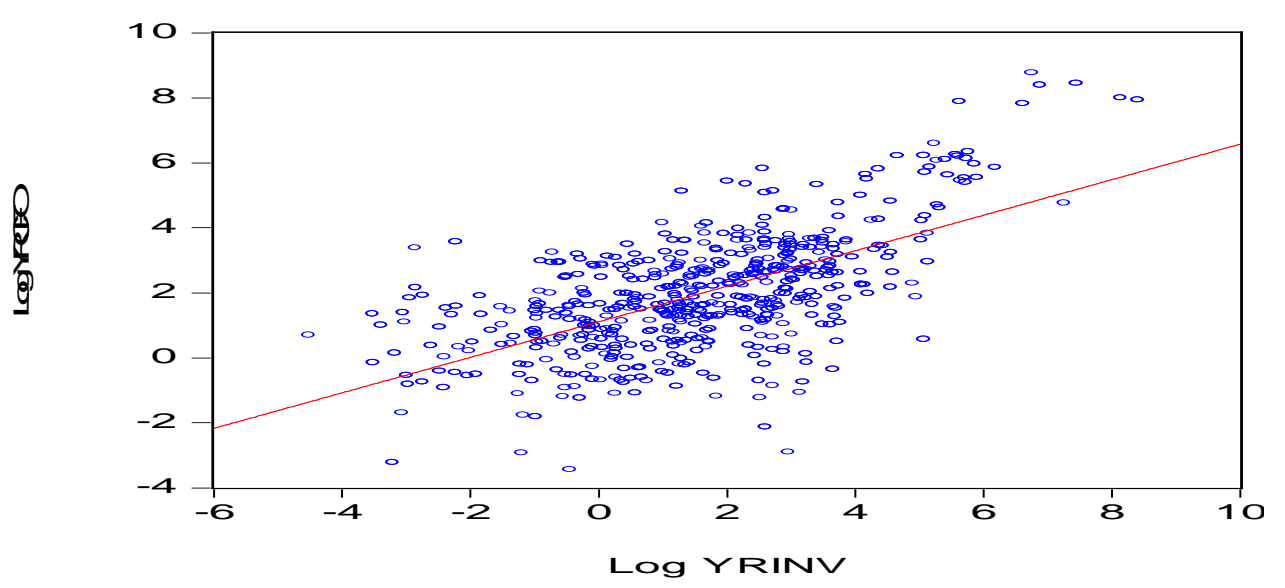


The above presented representation supports the consideration of a linear model $(y=a+b x+\mathcal{E})$. Furthermore, assuming a positive coefficient (b) for the independent variable (x) is supported by previous empirical evidence showing that an increase in cash flow will determine an increase in investments. We therefore propose the following model in order to investigate our paper's research question related to the relation between investments and cash flow:

$$
\log \operatorname{Inv} v_{i t}=a_{0}+a_{1} \log C F O+a_{2} \log S+a_{3} Q+u_{i t}
$$

where all variables are log of the corresponding variables or the variables discussed in the research methodology section of the paper.

Using the data from our sample we obtain the following results:

\section{Table 1 Regression analysis}

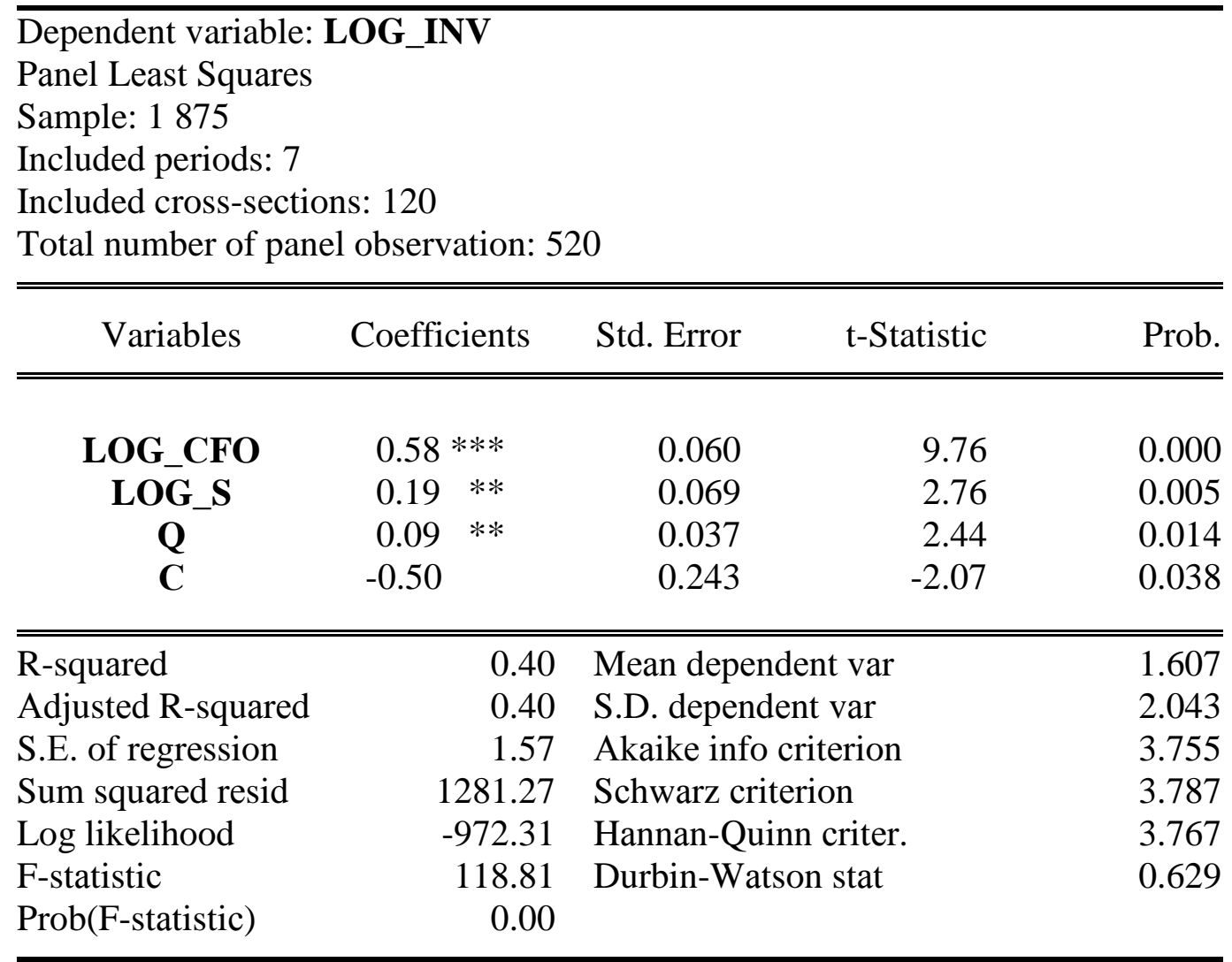

The results show that $40 \%$ of the investments variance is explained by cash flow variance and other variables taken together. The cash flow variable's coefficient is 0.58 suggesting that a $1 \%$ increase in operating cash flow will generate a $0.58 \%$ increase in investments. In depth analysis shows that results might be impacted due to the existence of unobserved factors that might influence investments. The Durbin-Watson test points out that the model is affected by factors which we did not consider. This might be the consequence of the fact that companies belong to different industries, have different size and might or might not be facing financial constraints. We therefore further develop the analysis by adding estimators that account for the fixed effects. 


\section{Table 2 Regression analysis - fixed effects}

\begin{tabular}{|c|c|c|c|c|}
\hline \multicolumn{5}{|c|}{$\begin{array}{l}\text { Dependent variable: LOG_INV } \\
\text { Panel Least Squares } \\
\text { Sample: } 1875 \\
\text { Included periods: } 7 \\
\text { Included cross-sections: } 120 \\
\text { Total number of panel observation: } 520\end{array}$} \\
\hline Variables & Coefficients & Std. Error & $\mathrm{t}$-Statistic & Prob. \\
\hline LOG_CFO & $0.27 * * *$ & 0.053 & 5.16 & 0.000 \\
\hline LOG_S & $0.32 * *$ & 0.147 & 2.20 & 0.027 \\
\hline $\mathbf{Q}$ & 0.01 & 0.026 & 0.39 & 0.689 \\
\hline $\mathbf{C}$ & -0.37 & 0.628 & -0.59 & 0.550 \\
\hline \multicolumn{5}{|c|}{$\begin{array}{l}\text { Cross-section fixed (dummy variables) } \\
\text { Period fixed (dummy variables) }\end{array}$} \\
\hline R-squared & 0.83 & \multirow{7}{*}{\multicolumn{2}{|c|}{$\begin{array}{l}\text { Mean dependent var } \\
\text { S.D. dependent var } \\
\text { Akaike info criterio } \\
\text { Schwarz criterion } \\
\text { Hannan-Quinn criter. } \\
\text { Durbin-Watson stat }\end{array}$}} & 1.607 \\
\hline Adjusted R-squared & 0.78 & & & 2.043 \\
\hline S.E. of regression & 0.95 & & & 2.950 \\
\hline Sum squared resid & 354.37 & & & 4.005 \\
\hline Log likelihood & -638.14 & & & 3.363 \\
\hline F-statistic & 15.61 & & & 1.829 \\
\hline Prob(F-statistic) & 0.00 & & & \\
\hline
\end{tabular}

The period under analysis (2005-2011) brought a series of changes for the Romanian economy. By only mentioning the economic crisis and the country becoming a member of the European Union, we might easily expect one period to be different from the other. Being a EU member might also have brought more foreign capital and access to more refundable and non-refundable funds which may further influence company's investments. When considering fixed effects, our results improve, as we can see from the Durbin-Watson test, initially pointing problems with the first results. The coefficients maintain their relevance, further documenting the relevance of the model. The independent variable which is the focus of our analysis ( $\log \mathrm{CFO}$ ) is still representative at a significance level of 0.0001 , though its coefficients dropped more than $50 \%$ (from 0.58 to 0.27 ).

Comparing the model can also be done by using the Akaike Information Criterion, also pointing towards the second model as being more suitable. The Schwarz criterion follows the same principle as Akaike, but puts more emphasis on the free parameters. Again, the second model is preferred. Comparing the R-squared in the two models we see a significant increase (from $40 \%$ to $83 \%$ ). As R-squared may increase artificially due to including more (dummy) variables into the model, we must also analyze the Adjusted R-squared in order to avoid „overfitting”. As Adjusted R-squared (0.78) is close to R-squared (0.83) we may anticipate a minimum contraction of this indicator. Further testing imposes in depth analysis of the independent variables. 


\section{Table 3 Matrix of independent variables correlation}

\begin{tabular}{|c|c|c|c|}
\cline { 2 - 4 } \multicolumn{1}{c|}{} & LOG_CFO & LOG_S & Q \\
\hline LOG_CFO & 1.00 & - & - \\
\hline LOG_S & $\mathbf{0 . 7 6}$ & 1.00 & - \\
\hline $\mathbf{Q}$ & 0.01 & -0.02 & 1.00 \\
\hline
\end{tabular}

The above presented table shows a high level of correlation between log_CFO (log of operating cash flow) and log_S (log of sales) documenting that our model displyas multicollinearity. This is a problem often met in accounting research making it difficult to establish precise estimates of the coefficients in regression analysis. A series of strategies were used in order to respond to this problem, but were further debated by other studies arguing that it does not improve results. What we did is try to eliminate one of the problematic variables, and as cash flow is the focus of our analysis, we looked at the model without considering sales. The results therefore obtained still show an R-squared of 0.83 documenting that the explanatory power of the model did not diminish, coupled with an F statistic of 15.55, slightly below the previous one, documenting that the model is significant. The cash flow related variable does not record any relevant changes. In such a case literature recommends to keep the excluded variable in the model as excluding it might cause new problems (Gujarati, 2004).

\section{CONCLUSIONS AND DISCUSSIONS}

Previous empirical studies focusing on the relation between corporate cash flow and investments cluster the sample based on size, industry and many use financial constrains as a classification criteria as well. They mainly reach the conclusion that the influence of cash flow on investment is stronger for companies with financial constrains as for them internal capital is not perfectly replaceable with external capital. This is due to the fact that companies going through periods of economic instability (including low and volatile cash flow) bear higher risks as perceived by creditors and this generates an increase in interest. For companies this spells into an increase in the cost of external capital. When needing money, companies with financial constrains can not reach external capital as easy as companies without financial constrains do. In this context companies that face financial constrains become much more dependent on the health of cash flow.

Literature uses different proxies for financial constrains. One would be the ratio between the profit remaining in the company and the net result. The lower the ratio, the better the economic condition of the company should be as this would mean the company is paying dividends to shareholders, decision that would be approved in cases when remaining resources are enough to cover all necessities. Fazzari et al. (1988) and Gilchrist and Himelberg (1995) use the level of paid dividends, assessing a company that pays low dividends as facing financial constrains. We will further use this criterion to complete the analysis developed on our sample. Dividends and investments represent competing elements, therefore companies facing financial constrains having to maintain profits within the entity in order to be able to finance their activity.

The below presented graph 2 illustrates companies which can be characterized as having a favorable financial situation (not facing financial constrains). It is easy to observe how the evolution of cash flow differs from that of investments. In such cases operating cash flow and investments are not connected due to the fact that the companies can easily replace internal capital with external capital. On the other hand, graph 3 illustrating companies which can be characterized as having an 
unfavorable financial situation (facing financial constrains) documents the opposite, cash flow and investments having similar evolutions.

\section{Graph 2 Evolution of CFO and INV for companies not facing financial constrains}

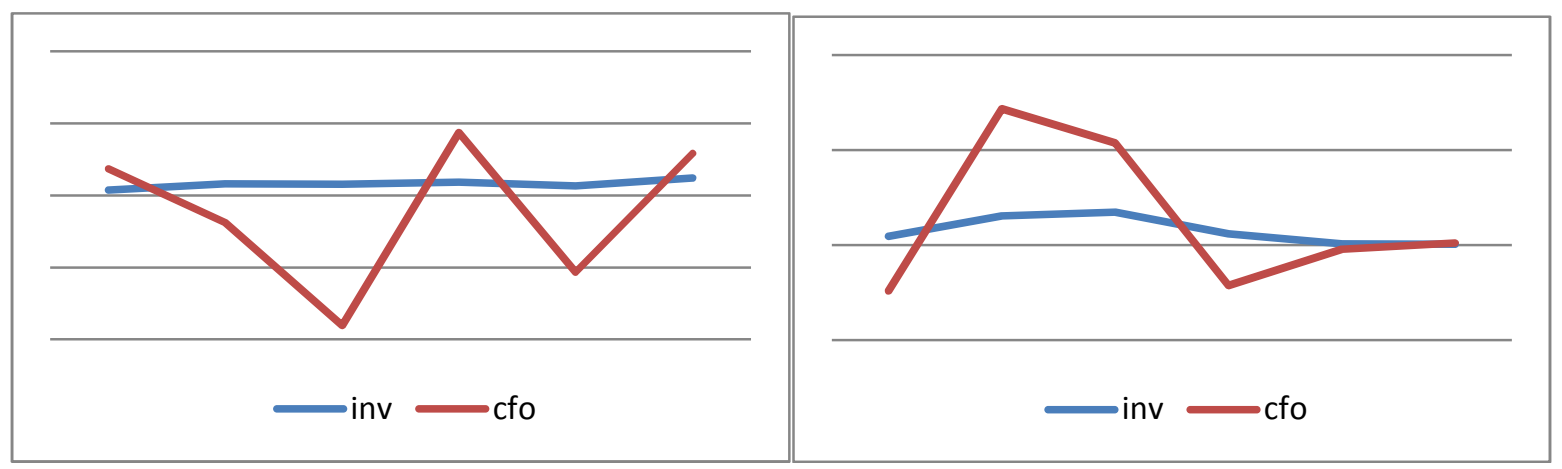

Graph 3 Evolution of CFO and INV for companies facing financial constrains
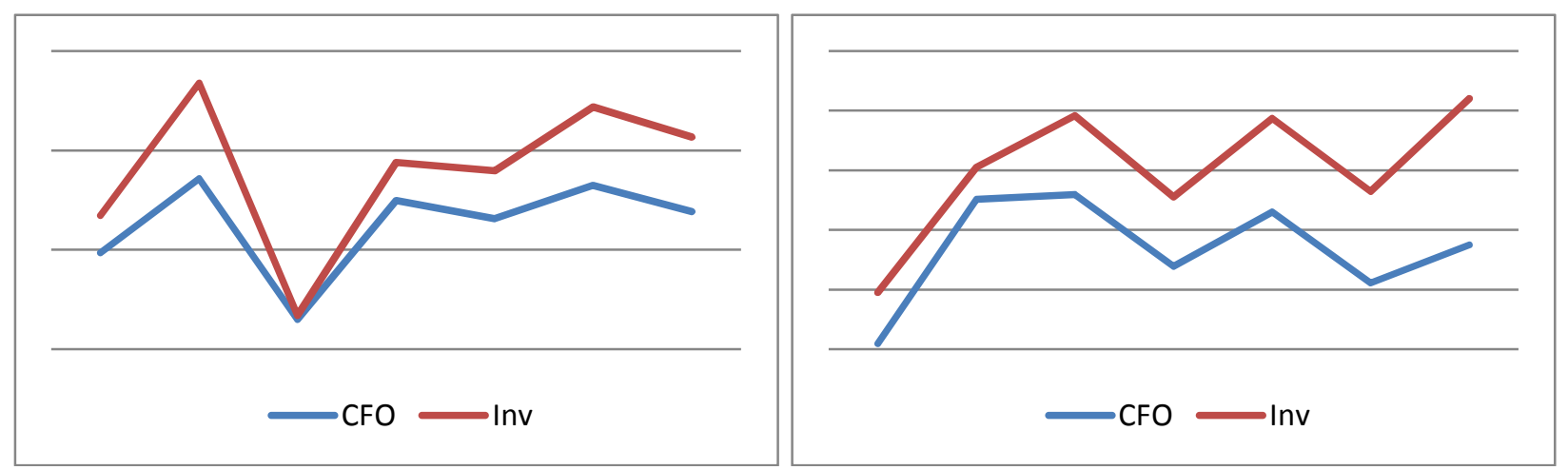

The evolutions of cash flow and investments differ significantly when comparing the two categories of companies. There is no doubt that the results of our study are impacted by the sample including a high number of companies which, based on proxies used by previous studies, can be characterized as facing financial constrains. Out of the 125 companies in our sample, only 18 paid dividends, and even those did not do it constantly over the analyzed period.

Overall we can conclude that there is a significant positive association between investments and cash flow in the context of Romanian listed companies. A $1 \%$ cash flow fluctuation generates a $0.27 \%$ change in the planed investments. Among the limitations of our study we must mention the following. We did not separate the companies by several classification criteria as done by previous studies. This is due to the relatively low number of companies in the sample which, for criteria such as industry, would have led to a number of companies per industry that would not have allowed us to test the proposed model. Our paper focuses on the relation between investments and cash flow which is empirically tested, without considering the cost of capital which is also informative. The model is only tested based on annual data due to limitations in terms of information being available. This excludes the consideration of cash flow volatility during the financial reporting period. The information available on Romanian companies (or better said lack of) also limits the number of control variables being used. Limitations help identify perspectives for future developments over the proposed research question. Further developments of the study should consider adding control variables that would allow testing of the model's robustness, finding new proxies in order to identify those companies facing financial constrains, adding the cost of capital as a determinant of investments into the analysis and of course considering cash flow volatility during the year. 


\section{REFERENCES}

Abel, A.B. \& Eberly, J.C. (2011). How Q and Cash Flow Affect Investment without Frictions: An Analytic Explanation, Review of Economic Studies, vol. 78, pp. 1179-1200.

Baker, M., Stein, J. C. \& Wurgler, J. (2003) When Does the Market Matter? Stock Prices and the Investment of Equity-Dependent Firms, The Quarterly Journal of Economics, vol. 118, pp. 969-1005.

Ciccolo, J. \& Fromm, G. (1979) "Q" and the Theory of Investment, The Journal of Finance, Vol. XXXIV, No.: 2, pp. 535-547.

Cleary, S. (1999) The Relationship between Firm Investment and Financial Status, Journal of Finance, vol. 54, no.: 2, pp. 673-692.

Fazzari, S.M., Hubbard, R.G., Petersen, B.C., Blinder, Alan S. \& Poterba, J.M. (1988) Financing Constraints and Corporate Investment, Brookings Papers on Economic Activity, vol. 1988, no.: 1, pp. 141-206.

Gilchrist, S. \& Himmelberg, C.P. (1995) Evidence on the role of cash flow for investment, Journal of Monetary Economics, vol. 36, no.: 3, pp. 541-572.

Gujarati, D.N. (2004) Basic Econometrics, McGraw-Hill International Editions, 4th edition.

Kaplan, S.N. \& Zingales, L. (1997) Do investment-cash flow sensitivities provide useful measures of financing constraints? Quarterly Journal of Economics, vol. 112, pp. 169-215.

Richardson, S. (2006) Over-investment of free cash flow, Review of Accounting Studies, vol. 11, pp. 159189.

Shimko, D. (1997) Yearnings per share, Risk, vol. 10, pp. 37.

Stancu, I. (2002) Finanţe, Editura Economică, Bucureşti. 